\title{
Belgium
}

On the initiative of its Junior Section, the Belgian Red Cross has organized a competition amongst the young of drawings relating to the Geneva Conventions.

This idea met with the greatest success, as can be seen when one looks through the excellent review Jeunesse Servir, which gives a selection of some of these drawings. This is a most effective method of teaching. It is in fact certain that young people, having been given the opportunity of thinking about the Geneva Conventions, first of all in their choice of subject, then in their drawings in relation to the texts, will retain in their minds the humanitarian principles thus illustrated.

Furthermore, the Belgian Ministry of Education and Culture has decided to organize a mobile exhibition of 126 drawings selected from the best entries submitted to the competition. This exhibition will certainly contribute to awaken interest in the Geneva Conventions in Belgium. The Red Cross world should be appreciative of this most enterprising undertaking.

\section{Great Britain}

The periodical News Review of the British Red Cross Society has published a special number dedicated to the Centenary of our movement. It gives a good outline of the numerous activities of this $N$ ational Society and we will quote some passages from its introductory article.

To the ordinary man in the street the image of the Red Cross is unreservedly associated with the relief of suffering in wartime. This is understandable, for the movement was born out of war to operate primarily in time of war. But a century of history has extended its work to helping those in need whenever and whereever they are. 